Upton, New York 11973

RHIC TECHNICAL Note No. 28

RHIC Decapole Correction Magnet Requirements

F. Dell, H. Hahn, G. Parzen, A. Ruggiero

August 17,1987 


\section{RHIC Decapole Correction Magnet Requirements}

\section{F. Dell, H. Hahn, G. Parzen, A. Ruggiero}

\section{Introduction}

The need for corrector magnets to compensate the systematic saturationinduced decapole error in RHIC dipoles was pointed out in a previous report. In the present note, results from more detailed analytic and tracking studies are summarized. The most important aspect of this study was the recognition that the tune shift due to the saturation $b_{4}$ can only be partially corrected and that the residual tune shifts are at the tolerance limit for nominal beam intensities. The conclusion was reached that a reduction of $b_{4}$ at the source is required in order not to preclude future luminosity improvements in RHIC.

\section{The tuneshift due to decapole errors}

The horizontal and vertical betatron tune shifts caused by decapole fields can be written in linear approximation as

$$
\begin{aligned}
& \Delta \nu_{\mathrm{x}}=\delta\left(\mathrm{h}_{\mathrm{p}} \delta^{2}+\mathrm{h}_{\mathrm{x}} \varepsilon_{\mathrm{x}}+\mathrm{h}_{\mathrm{y}} \varepsilon_{\mathrm{y}}\right) \\
& \Delta \nu_{\mathrm{y}}=\delta\left(\mathrm{v}_{\mathrm{p}} \delta^{2}+\mathrm{v}_{\mathrm{x}} \varepsilon_{\mathrm{x}}+\mathrm{v}_{\mathrm{y}} \varepsilon_{\mathrm{y}}\right)
\end{aligned}
$$

with $\varepsilon$ defined by the betatron function and the betatron amplitude $A_{B}$

$$
\varepsilon=\frac{\pi A_{B}^{2}}{\beta}
$$

and the momentum error

$$
\delta=\frac{\Delta \mathrm{p}}{\mathrm{p}} \text {. }
$$

Analytical expressions for the coefficients are given by 2,3

$$
\begin{aligned}
& h_{p}=\ldots \frac{1}{\pi \rho} \int b_{4} \beta_{X} x_{p} 3 d s \\
& h_{x}=\frac{3}{4 \pi \rho} \int b_{4} B_{x}^{2} x_{p} d s \\
& h_{y}=-\frac{3}{2 \pi \rho} \int b_{4} \beta_{y} \beta_{x} x_{p} d s \\
& v_{p}=-\frac{1}{\pi \rho} \int b_{4} B_{y} x_{p} 3 d s \\
& v_{X}=-\frac{3}{2 \pi \rho} \int b_{4} \beta_{x} \beta_{y} x_{p} d s \\
& v_{y}=\frac{3}{4 \pi \rho} \int \cdot b_{4} \dot{\beta}_{y}^{2} x_{p} d s
\end{aligned}
$$

where $p$ is the bending radius in the dipoles and the integrals have to be evaluated over the entire ring, i.e., all dipoles and corrector magnets. 
In Table I, the numerical values for the tuneshift coefficients obtained from the above analytical expressions are listed (A) and compared with tracking results $(\mathrm{T})$. In order to highlight the relative strength of the various contributions, the coefficients in Table I are normalized to the nominal momentum spread and the $6 \sigma$ emittance of Au beams at $100 \mathrm{GeV} / \mathrm{amu}$

$$
\begin{aligned}
& \varepsilon_{A u}=1.8 \pi \times 10^{-6} \mathrm{~m} \\
& \delta_{A u}=2.6 \times 10^{-3}
\end{aligned}
$$

and it is assumed that $\varepsilon_{\mathrm{X}}+\varepsilon_{\mathrm{y}}=\varepsilon_{\mathrm{Au}}$. The normalized tuneshift expressions now read

$$
\begin{aligned}
& \Delta v_{x}=D\left[H_{p} D^{2}+H_{x} E-H_{y}(1-E)\right] \\
& \Delta v_{y}=-D\left[V_{p} D^{2}+V_{x} E-V_{y}(1-E)\right]
\end{aligned}
$$

with

$D=\delta / \delta_{A u}$

and

$\mathrm{E}=\varepsilon_{\mathrm{X}} / \varepsilon_{\mathrm{Au}}$.

\begin{tabular}{|c|c|c|c|c|}
\hline & & Dipole* & $\begin{array}{c}\text { Corrector } \\
@ \mathrm{QF}\end{array}$ & $\begin{array}{c}\text { Corrector } \\
@ Q D\end{array}$ \\
\hline & & $\times b_{4}^{\prime}$ & $\times b_{F}^{\prime} \ell / L$ & $\times b_{D}^{\prime} \ell / L$ \\
\hline $\mathrm{H}_{\mathrm{p}}$ & $\begin{array}{l}\mathrm{A} \\
\mathrm{T}\end{array}$ & $\begin{array}{l}3.0 \\
2.68\end{array}$ & $\begin{array}{l}6.85 \\
6.6\end{array}$ & $\begin{array}{l}0.25 \\
0.14\end{array}$ \\
\hline $\mathrm{H}_{\mathrm{X}}$ & $\begin{array}{l}A= \\
T\end{array}$ & $\begin{array}{l}13.34 \\
12.14\end{array}$ & $\begin{array}{l}27.43 \\
30.58\end{array}$ & $\begin{array}{l}0.75 \\
0.47\end{array}$ \\
\hline $\mathrm{H}_{\mathrm{y}}$ & $\begin{array}{l}\mathrm{A} \\
\mathrm{T}\end{array}$ & $\begin{array}{l}20.03 \\
17.03\end{array}$ & $\begin{array}{l}12.19 \\
11.84\end{array}$ & $\begin{array}{l}6.73 \\
4.81\end{array}$ \\
\hline $\mathrm{V}_{\mathrm{p}}$ & $\begin{array}{l}\mathrm{A} \\
\mathrm{T}\end{array}$ & $\begin{array}{l}2.7 \\
1.99\end{array}$ & $\begin{array}{l}1.53 \\
1.19\end{array}$ & $\begin{array}{l}1.15 \\
0.80\end{array}$ \\
\hline $\mathrm{V}_{\mathrm{X}}$ & $\begin{array}{l}\mathrm{A} \\
\mathrm{T}\end{array}$ & $\begin{array}{l}20.03 \\
16.14\end{array}$ & $\begin{array}{l}12.19 \\
10.12\end{array}$ & $\begin{array}{l}6.73 \\
4.71\end{array}$ \\
\hline $\mathrm{v}_{\mathrm{y}}$ & $\begin{array}{l}\mathrm{A} \\
\mathrm{T}\end{array}$ & $\begin{array}{r}11.66 \\
9.88\end{array}$ & $\begin{array}{l}1.36 \\
0.54\end{array}$ & $\begin{array}{l}15.14 \\
14.46\end{array}$ \\
\hline
\end{tabular}

Table I. Decapole tune shifts of $\mathrm{Au}$ ions at $100 \mathrm{GeV} / \mathrm{amu}$ with $\delta=2.6 \times 10^{-3}$ and $\varepsilon=1.8 \pi \times 10^{-6} \mathrm{~m}$ 
Using the values of Table $I$ and the expected $b_{4}^{\prime}=6 \times 10^{-4}$ one finds the uncorrected tune shifts for the nominal Au beams at $100 \mathrm{GeV} / \mathrm{amu}$ of

$$
\begin{array}{llll} 
& \Delta \nu_{\mathrm{H}} & \Delta \nu_{\mathrm{V}} \\
\mathrm{E}=0 & \mp 10.2 & \mp 5.4 & \times 10^{-3} \\
\mathrm{E}=1 & \mp 9.8 & \mp 13.6 & \times 10^{-3}
\end{array}
$$

Tuneshifts of this magnitude are unacceptably large and correction of the saturation induced decapole in the dipoles is required.

\section{Correction of the decapole error}

Complete correction of the tune shift due to the decapole error with a two family decapole corrector system, (one family each at $Q F$ and $Q D$ ) is not possible. Therefore an rms minimization of the residual error was considered. One approach would be to require that for the nominal particle

$$
F=F\left(b_{F}, b_{D}\right)=\int_{0}^{1}\left(\Delta v_{x}^{2}+\Delta v_{y}^{2}\right) d E=\operatorname{Min}
$$

leading to a linear set of equations in $b_{F}$ and $b_{D}$

$$
\frac{\partial F}{\partial b_{F}}=0 \text { and } \frac{\partial F}{\partial b_{D}}=0
$$

Another approach suggested by Parzen is to require only that the function

$$
F=F\left(b_{F}, b_{D}\right)=\left(\Delta v_{x}^{2}+\Delta v_{y}^{2}\right)_{E=0}+\left(\Delta \nu_{x}^{2}+\Delta v_{y}^{2}\right)_{E=1}=\text { Min }
$$

In view of the linear dependence of the tune shifts on the corrector strength, a simpler and in fact better solution, suggested by Hahn, is obtained by requiring

$$
\Delta v_{X}(E=0)=\Delta v_{X}(E=1)=\Delta \nu_{y}(E=0)
$$

leading to the 2 linear equations in $b_{F}$ and $b_{D}$

$$
\mathrm{H}_{\mathrm{x}}+\mathrm{H}_{\mathrm{y}}=0
$$

and

$$
\mathrm{H}_{\mathrm{y}}-\mathrm{H}_{\mathrm{p}}+\mathrm{V}_{\mathrm{y}}-\mathrm{V}_{\mathrm{p}}=0
$$


The decapole corrector strengths required follows as

$$
\begin{aligned}
b_{F} l & =-0.633 b_{4} L \text { (analytical) } \\
& =-0.554 b_{4} L \text { (tracking) } \\
b_{D} l & =-1.107 b_{4} L \text { (analytical) } \\
& =-1.075 b_{4} L \text { (tracking) }
\end{aligned}
$$

The residual tune shifts for the nominal Au particle after correction now become, based on analytical as well as tracking results,

$$
\Delta v_{\mathrm{X}}, \Delta v_{\mathrm{y}}= \pm 3.9 \times 10^{-3}
$$

This tune shift would be acceptable, however, in order to preserve the possibility of future improvements in the beam intensity, a reduction of the saturation decapole in the dipole would be desirable.

\section{References:}

1. H. Hahn, Report AD/RHIC-22 (1987)

2. A. Jackson, report SSC-107 (1987)

3. A. G. Ruggiero, report AD/RHIC-AP-47 (1987) 